\title{
Range of Motion, Abduction
}

National Cancer Institute

\section{Source}

National Cancer Institute. Range of Motion, Abduction. NCI Thesaurus. Code C139212.

An assessment of joint flexibility that measures the movement of a body part pulling away from the midline of the body, in number of degrees. 